\title{
Como funciona o Patent Prosecution Highway
}

\author{
Diego Boschetti Musskopf * \\ Yoshitoshi Tanaka ** \\ Edi de Oliveira Braga Junior ${ }^{* * * *}$ \\ Adelaide Maria S. Antunes ${ }^{* * * *}$ \\ Rockfeller Maciel Peçanha ${ }^{* * * * * *}$
}

Resumo: O estudo tem por objetivo apresentar o funcionamento dos diferentes tipos de acordo Patent Prosecution Higway (PPH), sem julgamento de mérito. Metodologia: foram estudados os acordos assinados pelos principais Escritórios de Patente (PTO), bem como feita uma revisão bibliográfica sobre o assunto. Principais Resultados: $O$ PPH aproveita a sinergia entre o work-sharing e do exame antecipado. A ideia central é que o PTO que faça o exame primeiro forneça os dados do exame para que os demais utilizem como subsídio. O requerente é estimulado a participar do work-sharing "em troca" do benefício do exame antecipado: se ele restringir suas reivindicações à matéria considerada patenteável no primeiro PTO, ele poderá antecipar o exame nos demais PTOs. Conclusão: Há vantagens e desvantagens para os PTOs, para os usuários do sistema de Propriedade Intelectual e para a sociedade. Cada país deve avaliar os prós e contras antes de assinar o acordo.

Palavras-chave: $\mathrm{PPH}$, exame prioritário, work-sharing.

Classificação JEL: F530; K200; K330

\footnotetext{
* Doutorando em Inovação, Propriedade Intelectual e Desenvolvimento na Universidade Federal do Rio de Janeiro (Brasil). E-mail: diego.musskopf@ie.ppge.br

** Professor da Universidade de Tokyo Institute of Technology (Japão). E-mail: ytanaka@mot.titech.ac.jp

*** Pesquisador Instituto nacional da propriedade Industrial (INPI). E-mail: edibraga@inpi.gov.br

**** Professora da Academia de Propriedade Intelectual do INPI, Professora emérita da UFRJ e Professora da Escolade Química da UFRJ. E-mail: adelaide@eq.ufrj.br.

***** Professor da Universidade Estácio de Sá (Brasil). E-mail: rockrio@hotmail.com
} 


\section{Introdução}

Com o avanço da globalização, tem havido uma procura crescente pela proteção de direitos de propriedade industrial da mesma invenção em um número cada vez maior de países. Isto levou a um número crescente de pedidos "correspondentes" (de mesma família e matéria similar) depositados em vários países, facilitados por acordos internacionais. A Gráfico 1 mostra o aumento da proporção de pedidos de não-residentes em relação a residentes no somatório de todos os Escritórios de Patentes.

\section{Gráfico 1: Número de pedidos depositados por residentes e não-residentes}

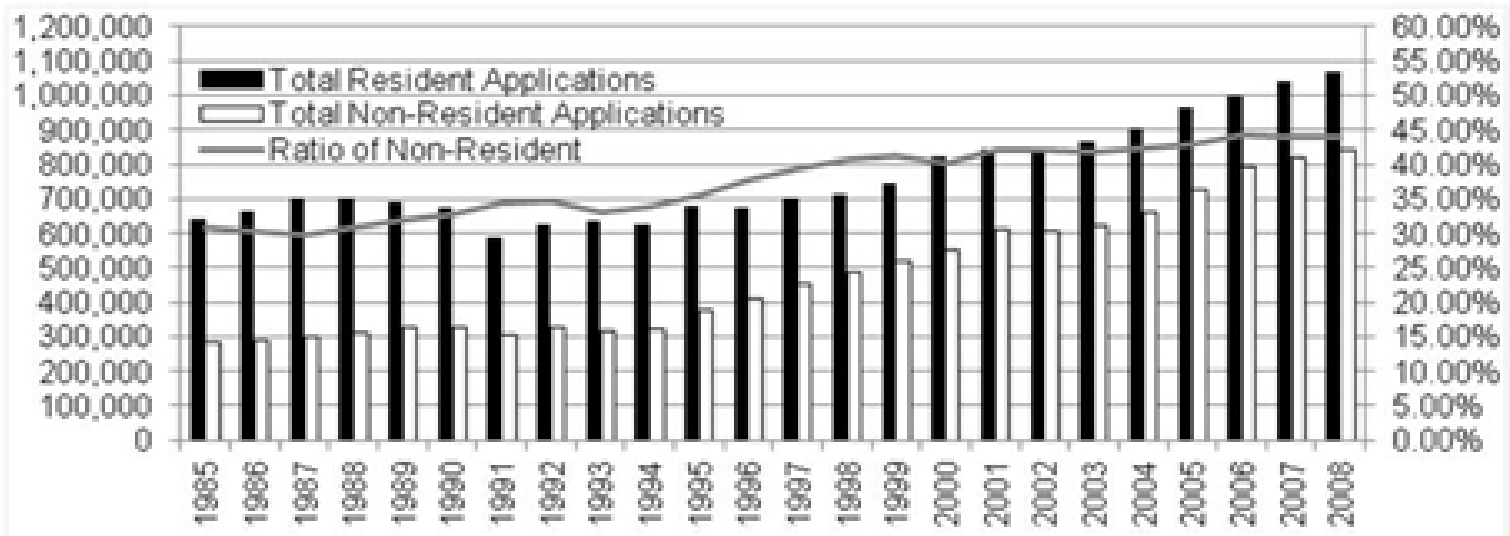

Fonte: World Intellectual Property Indicators, 2011 edition (World Intellectual Property Organization, 2011)

Entretanto, a capacidade de análise dos pedidos de patente da maioria dos escritórios de patente não tem acompanhado essa demanda por motivos de infraestrutura adequada, falta de apoio administrativo, pela quantidade insuficiente de examinadores de patente, bem como dificuldade de encontrar examinadores com conhecimento adequado para as tecnologias de ponta. Assim, a dificuldade dos escritórios em atender o rápido aumento do número de depósito de pedidos de patente resulta em backlog ${ }^{1}$ (Maeda, 2011):

"Increasingly complex technologies appear to have resulted in patent applications that are both lengthy and potentially more difficult for examiners to parse. In addition, technological innovation is today a global phenomenon that is occurring at an increasingly rapid pace. As compared to previous years, USPTO examiners may face more difficulty in locating the most pertinent documents that describe the state of the art. Of course, the increasing number of patent applications - along with a large backlog of unexamined applications - also potentially impacts the ability of the USPTO to maintain high levels of patent quality" (Thomas, 2011).

\footnotetext{
10 termo "backlog" refere-se ao acumulo de trabalho (de qualquer natureza) à espera de ser feito ou de ordens a serem cumpridas. Não existe uma definição ou cálculo único utilizado por todos os Escritórios de Patentes (PTOs). No caso do texto, o termo refere-se ao número de pedidos de patente pendentes de decisão.
} 
Existem várias maneiras de reduzir o backlog ou seus efeitos negativos. A colaboração de trabalho entre os Escritórios de Patente através de acordos internacionais (denominado work-sharing ${ }^{3}{ }^{4}$ ) vêm crescendo em vontade e necessidade com o aumento do número de pedidos (Japan. Japan Patent Office, 2008). Estes acordos tem o objetivo de favorecer a velocidade das decisões dos escritórios através do compartilhamento de informações (Figura 1). Ou seja, o primeiro escritório que realizar a análise do pedido de patente disponibiliza os resultados para consulta e utilização pelo segundo escritório evitando a duplicação de esforços (Japan. Japan Patent Office, 2008).

Figura 1: Diferentes níveis de work-sharing

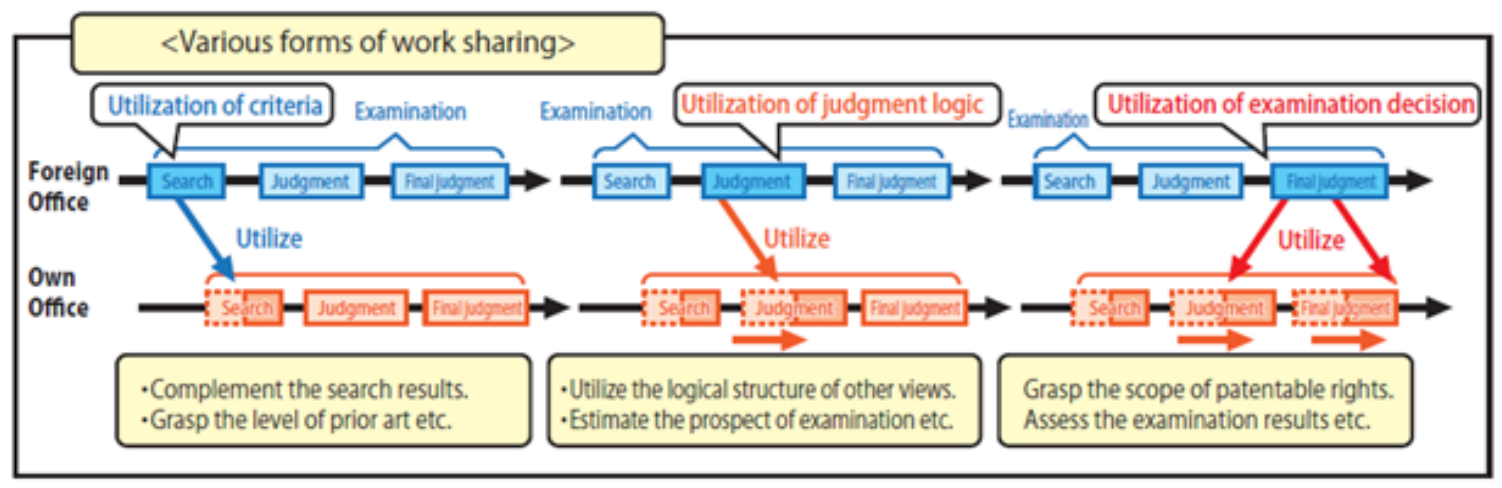

Fonte: JPO Annual Report 2011 (Japan. Japan Patent Office, 2011)

Além do mais, através do work-sharing os examinadores do PTO que realizam o exame depois podem "entender" os procedimentos, bem como a forma como os examinadores dos outros fazem a busca, o julgamento e a decisão. Caso seja do interesse da Nação receptora, ela solicitar que seu Escritório de Patente adapte seus próprios procedimentos internos ou altere seu entendimento dos requisitos de patenteabilidade (novidade, atividade inventiva e aplicação industrial) para atingir (ou não) maior homogeneidade ${ }^{5}$ com os demais escritórios (Japan. Japan Patent Office, 2011).

2 Uma discussão ampla sobre as formas de combater o backlog pode ser observada no trabalho de Musskopf \& Tanaka (2012).

3 A tradução literal do termo em inglês "work-sharing" para português é "divisão de trabalho". Contudo, tal tradução pode induzir uma interpretação equivocada de que "cada escritório faz apenas uma parte do trabalho e delega a outra parte do trabalho a outro escritório". Essa não é uma característica do PPH em sí, embora cada escritório possa adotar essa postura individualmente. Por conseguinte, prefere-se utilizar a expressão "compartilhamento de trabalho" neste trabalho que corresponde a "permitir que os Escritórios de Patente tenham acesso ao trabalho efetuado por outros Escritórios como forma de subsídio ao exame" e traduz melhor o conteúdo semântico pretendido. Ou seja, o trabalho não é dividido entre os escritórios, mas sim, seus resultados feitos individualmente são tornados acessíveis.

4 Diversas formas de work-sharing utilizadas pelos escritórios mais proeminentes podem ser vistas no trabalho de Musskopf \& Tanaka (2012).

5 A questão da homogeneidade dos sistemas de patentes está sendo amplamente discutida, mas não pertence ao escopo desse trabalho. Em linhas gerais, os defensores de um sistema patentário mais homogêneo alegam que ela criará um "ambiente institucional" mais propício à inovação, pois ele aumentará a segurança jurídica dos titulares sobre os seus inventos. Desse modo, eles se sentirão mais "à vontade" para transferir sua tecnologia para outras empresas sem o receio de que ela será "roubada" ou "espalhada" no mercado. Por outro lado, os contrários a homogeneidade alegam que um sistema de proteção uniforme impedirá que os países em desenvolvimento adequem os padrões de patenteabilidade de suas leis (principalmente relacionadas com o nível de atividade inventiva) para ser compatível com o desejado e necessário ao desenvolvimento de sua indústria local. 
Por outro lado, o exame antecipado ${ }^{6} 7$ é um serviço que pode ser disponibilizado pelos Escritórios de Patentes que (não reduz o volume, mas) mitiga o problema do atraso de decisões dos Escritórios de Patente para "casos especiais" (por exemplo, inventos que precisam da patente concedida para serem negociados com o governo ou único medicamento para tratar certa doença). Além disso, o exame antecipado pode intensificar o work-sharing, pois o escritório que efetuar o exame primeiro poderá disponibilizar o resultado para os demais antecipadamente (Japan. Japan Patent Office, 2008).

Os escritórios que examinam depois, não precisam aceitar a decisão do primeiro, mas podem utilizá-lo como base para suas próprias decisões e assim reduzir seu tempo de busca, julgamento e decisão - este é motivo dos pedidos PCTs serem antecipados nas Autoridades de Busca Internacionais (ISA) e nas Autoridades de Exame Preliminar Internacionais (IPEA). Assim, os demais Escritórios se beneficiam do trabalho feito no escritório anterior - ou seja, o exame antecipado melhora a eficiência do work-sharing, mesmo que os escritórios não concordem completamente um com o outro (Musskopf \& Tanaka, 2012).

Contudo existe uma questão em aberto do work-sharing. Mesmo que o Segundo Escritório concorde plenamente com o exame do Primeiro, ele terá que emitir um parecer "semelhante", pois precisa solicitar ao requerente que faça as mesmas alterações no pedido. Ou seja, o Segundo Escritório não consegue usufruir plenamente do work-sharing e isso pode ser considerado um "desperdício" para o requerente e para o escritório, pois será efetuada uma ação "repetida" em dois PTOs (Musskopf \& Tanaka, 2012).

É preciso que o requerente participe do work-sharing para evitar esse desperdício. Ou seja, o requerente precisa fazer as alterações solicitadas pelo Escritório que examinou primeiro nos pedidos "correspondentes" depositados em outros Escritórios, restringindo o quadro reivindicatório antes que estes comecem o exame e correndo o "risco" das alterações não serem aceitas. Logo somente as reivindicações aceitas pelo Primeiro Escritório serão analisadas pelos Segundos Escritórios e, assim, o work-sharing funcionará plenamente. Mas é necessário ceder "um benefício" para o requerente aceitar esse "risco" e essa "restrição" (Musskopf \& Tanaka, 2012).

\section{Patent Prosecution Highway}

O Patent Prosecution Higway (PPH) une os benefícios do work-sharing e do exame antecipado. A ideia central é que o Escritório que faça o exame primeiro

\footnotetext{
6 Os termos em inglês "accelerated examination" ou "expedit examination" são os mais difundidos entre os Escritórios de Patente e o meio acadêmico internacional. Contudo, a tradução literal da expressão para o português pode induzir a uma interpretação equivocada de "um exame feito de forma mais rápida". Da mesma forma, o termo "exame prioritário" tem uso corrente para situações particulares especificadas no direito de acesso à idosos aos serviços públicos no Brasil (assim também é sua tradução literal para outras línguas em outros países). Por conseguinte, prefere-se utilizar a expressão "exame antecipado" ("anticipated examination") nesse painel que corresponde a "fura-fila" e traduz melhor o conteúdo semântico do pretendido.

7 Diversas formas de exame acelerado utilizadas pelos escritórios mais proeminentes podem ser visto no trabalho de Musskopf \& Tanaka (2012).
} 
forneça os dados do exame para os demais e que o requerente seja 'estimulado' a colaborar na divisão do trabalho dos escritórios através do benefício do exame antecipado nos demais escritórios. Então, para participar do PPH, o requerente precisa apresentar o escopo do quadro reivindicatório igual (ou semelhante) ou mais restrito ao do determinado como patenteável e admissíveis na ação mais recente do escritório que examinou primeiro (exceto para as diferenças devido à tradução e formato) (Japan. Japan Patent Office, 2012?a).

Vale destacar que estes pedidos têm grande probabilidade de serem patenteados no país de origem; sendo assim, se os critérios de patenteabilidade forem similares, este pedido terá uma probabilidade ainda maior de ser patenteado nos demais Escritórios já na primeira ação. Se isso ocorrer o pedido "sairá da fila" e reduzirá o backlog. Assim temos como principal vantagem do PPH para os Escritórios a redução do número de etapas do exame e para os requerentes o exame antecipado. A primeira versão do PPH era definida como:

"The Patent Prosecution Highway (PPH) is a framework in which an application whose claims have been determined to be patentable in the Office of First Filing (OFF) is eligible to go through an accelerated examination in the Office of Second Filing (OSF) with a simple procedure upon an applicant's request. The PPH, through the exploitation of all the search/examination-related information of the OFF, (1) supports applicants in their efforts to obtain stable patent rights efficiently around the world and (2) reduces the search/examination burden and improves the quality of the examination of the major patent offices in the world” (Japan. Japan Patent Office, 2012?a).

Esta primeiro tipo é chamado apenas PPH (ou paris-rout-PPH). Duas outras estruturas foram criadas mais tarde: o PCT-PPH e o Mottainai. Todos os três tipos continuam em expansão. As exigências desses três tipos foram flexibilizadas algumas vezes para tornar o programa mais user-friendly. Isso significa que elas podem variar ligeiramente em cada acordo bilateral (Japan. Japan Patent Office, 2012?a). A maioria das mudanças é estimulada por reuniões entre os escritórios de patentes ou entre os escritórios e as associações industriais (Jipa, 2011).

Com o desenvolvimento do programa, outros conceitos entraram. Atualmente, de forma mais precisa, o PPH é um acordo internacional o qual permite ao depositante de um pedido de patente cujo pelo menos uma reivindicação tenha sido considerada patenteável em um Primeiro Escritório de Patentes, se restringirem o quadro reivindicatório do pedido "correspondente" a essa matéria patenteável em um Segundo Escritório que tenha assinado o acordo com o primeiro, solicitar o exame antecipado neste Segundo Escritório. Ou seja, o programa "estimula" os depositantes a contribuir com o work-sharing, concedendo o benefício do exame antecipado àqueles pedidos em que o requerente contribuir da maneira mais efetiva conhecida para o work-sharing - uma vez que é estipulada a matéria considerada patenteável em um escritório (que fez

8Diversas formas de exame acelerado utilizadas pelos escritórios mais proeminentes podem ser visto no trabalho de Musskopf \& Tanaka (2012). 
o exame primeiro), o requerente aceita restringir o quadro reivindicatório dos pedidos "correspondentes" a ela em outros escritórios em que queira antecipar o exame. Assim, a análise do segundo escritório será realizada somente no número reduzido de reivindicações evitando, desse modo, o retrabalho da análise do quadro reivindicatório inteiro.

Figura 2: Países assinantes do PPH

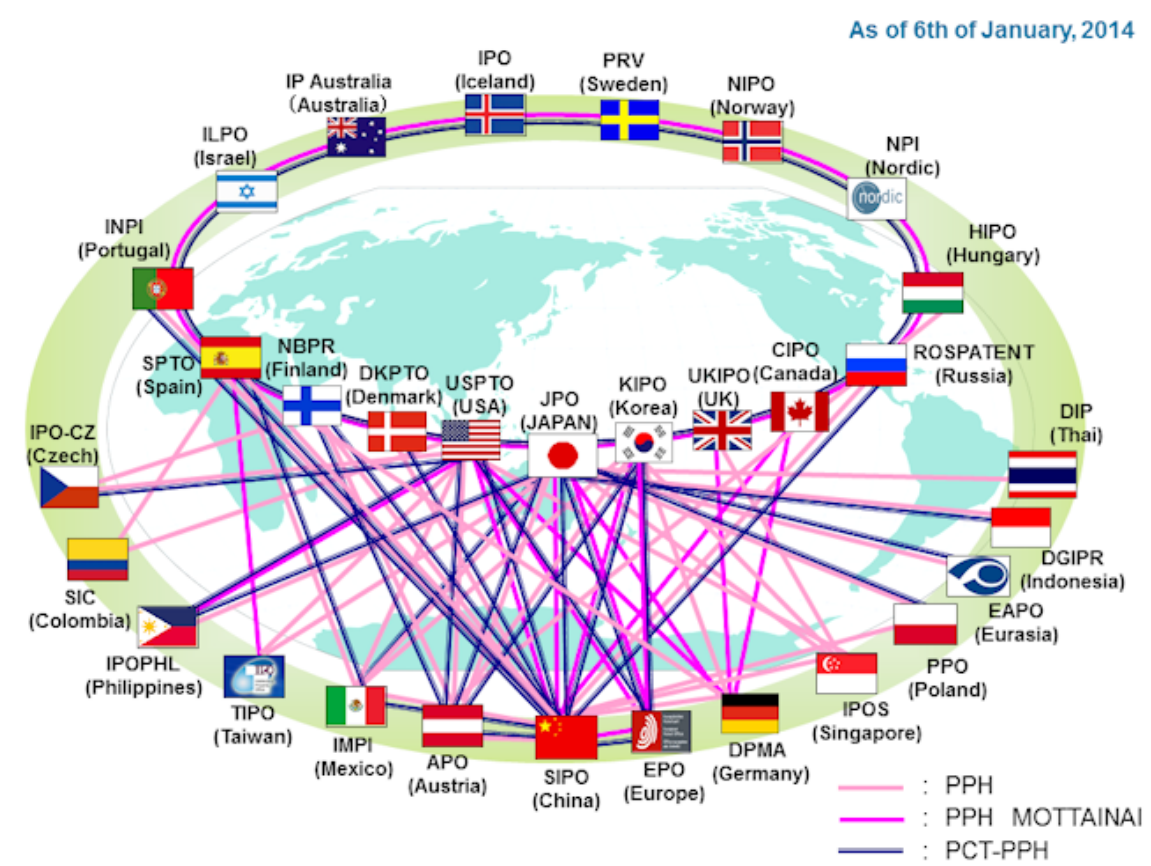

Fonte: PPH Portal website (Japan. Japan Patent Office, 2012?a)

O objetivo deste trabalho é apresentar as diferentes formas do Programa. Para tanto, foi feito uma revisão da bibliografia disponível.

\section{Como Funcionam os Diferentes Tipos de PPH}

Existem três variações do acordo PPH: o Paris-rout-PPH, o PCT-PPH, o PPH-Mottainai e o Global PPH. Cada um deles apresenta pequenas diferenças nas exigências.

\subsection{PPH (ou Paris-route-PPH)}

Este foi o primeiro programa lançado entre EUA e Japão e é o que apresenta o maior número de países signatários atualmente. Uma vez que se baseia em acordos bilaterais, há algumas diferenças em relação com os requisitos.

Este tipo é o que apresenta a estrutura mais simples. Suponha que um 
requerente deposite um pedido "A" primeiramente em um escritório de patentes membros do PPH. Este escritório recebe o título de Office of First Filing (Escritório de Primeiro Depósito ou OFF). Em seguida, o requerente deposita pedidos "correspondentes" em vários outros países. Os pedidos "correspondentes" podem ser:

1. um pedido que reivindique como prioridade válida, através da Convenção de Paris, o pedido correspondente depositado no OFF;

2. A fase nacional de um pedido PCT sem reivindicação de prioridade (direto PCT);

3. Um pedido que reivindica como prioridade valida, sob a Convenção de Paris, um pedido PCT sem reivindicação de prioridade;

Se qualquer um desses segundos países também for signatário do Parisroute-PPH, ele será chamado de Office of Second Filing (Escritório de segundo depósito ou OSF). O requerente poderá solicitar o exame antecipado de seu pedido em um ou mais OSF se (Figura 3):

1. o OFF determinou que há pelo menos uma reivindicação patenteável;

2. o exame não começou no $\mathrm{OSF}^{9}$;

3. a pedidos depositado no OSF é um "pedido correspondente" com depositado no OFF (e.g. o pedido reivindicar Paris prioritário no OSF);

4. todas as reivindicações do pedidos depositado no OSF ou correspondem suficientemente ou foram suficientemente alteradas para corresponder às reivindicações consideradas patenteáveis pelo OFF.

Figura 3: requerimentos do $\mathrm{PPH}$

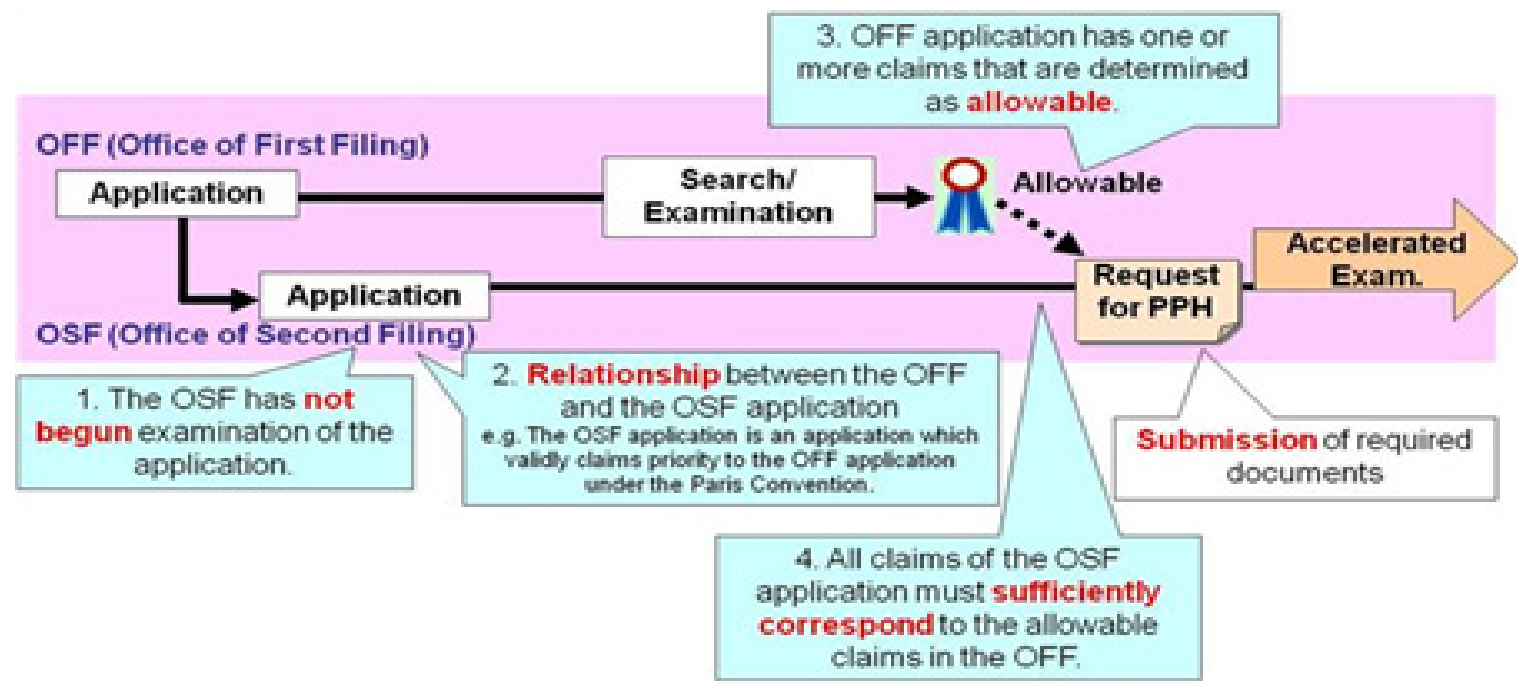

Fonte: JPO Annual Report 2011 (Japan. Japan Patent Office, 2011)

9 Alguns acordos PPH-Paris-route permitem que o requerente solicite o exame acelerado, mesmo que o exame já tenha começado no OSF (por exemplo, Coréia, Dinamarca, Finlândia, Áustria, Hungria e Espanha). 
É importante salientar que não é necessário ter a patente concedida, nem que o parecer do escritório (a ação oficial) seja pela concessão da patente, para que o pedido seja qualificado para requisitar o programa PPH nos OSFs. Contando que o parecer do OFF identifique quais as reivindicações atendem os critérios de patenteabilidade. Por exemplo, a ação do OFF pode ser uma "notificação de motivo para recusa por falta de unidade de invenção", mas deixa claro que "não foram encontrados motivos para a recusa por atividade inventiva nas reivindicações ' $\mathrm{x}$ "'.

As reivindicações consideradas "suficientemente correspondentes" são as que apresentam:

1. o mesmo ou semelhante escopo das determinadas como patenteáveis e admissíveis na ação mais recente escritório OFF (exceto para as diferenças devido à tradução e formato),

2. escopo pleiteado mais restrito do que o determinado como patenteável / permitido na ação mais recente do OFF.

Reivindicações que introduzem novas ou diferentes categorias das determinadas como patenteáveis / permitidas na ação mais recente do Office não são consideradas suficientemente correspondentes (por exemplo, converter reivindicação de produto por reivindicação de processo). a OSF:

Caso todos os requisitos sejam cumpridos, o requerente deve apresentar

1. uma cópia de todas as reivindicações e suas traduções;

2. uma cópia das ações do escritório estrangeiro suas traduções;

3. cópias de todos os documentos citados;

4. a tabela de correspondência das reivindicações.

Vários escritórios de patentes não exigem a "cópia das reivindicações e sua tradução", nem uma "cópia das ações OFF e sua tradução" se um (ou ambos) os documentos são fornecidos pelo "Dossier Access System" (Sistema de Acesso ao Dossier disponível entre os escritórios do USPTO, EPO e JPO). $\mathrm{O}$ requerente não é obrigado a apresentar os documentos citados do estado da arte na maioria dos escritórios se eles são documentos de patentes. No entanto, o candidato poderá ser solicitado a apresentá-lo pelo examinador de patentes no caso de o escritório de patentes tiver dificuldade em obtê-los. Por outro lado, o requerente é obrigado a apresentar o documento do estado da arte citado se não for literatura patentária.

Uma vez que o examinador OSF é capaz de ler todos os documentos do processo (incluindo a busca das anterioridades e os julgamentos), bem como recebe o pedido já está alterado, é esperado que a carga de exame reduza (Figura 1), da mesma forma que o número de "pareceres de ciência sobre a não patenteabilidade da invenção" ("razões de recusa"). É necessário ressaltar que o segundo examinador pode (ou não) aceitar o exame efetuado pelo primeiro examinador. 


\subsection{PPH-PCT}

O PPH-PCT começou em janeiro de 2010 em um acordo multilateral entre os escritórios dos EUA, Japão e EPO e vem sendo ampliado através de acordos bilaterais. A diferença dos procedimentos entre acordos é pequena. O quadro reivindicatório, os requisitos e documentos necessários são muito semelhantes ao Paris-rout- $\mathrm{PPH}$, com a diferença que este programa utiliza os produtos de trabalho do PCT como base para solicitar o PPH no segundo escritório.

Primeiramente, o requerente deposita o pedido internacional "A" em um escritório PCT receptor (PCT-RO) (este pedido pode reivindicar prioridade unionista de qualquer outro país assinante da Convenção de Paris). Este escritório recebe o título de "Escritório de primeiro depósito" (OFF) ou "Escritório exame prévio (OEE). Após isso, o requerente deposita pedidos correspondentes" em vários outros países. São considerados "pedidos correspondente" (Figura 4):

1. Os pedidos que se referem à fase nacional de um pedido internacional correspondente.

2. Os pedidos que reivindicam como prioridade seu pedido de depósito internacional (depositado via PCT) correspondente.

A Figura 4 apresenta as diversas "rotas" que os pedidos correspondentes podem tomar em diferentes países após o depósito internacional. Neste caso, o requerente faz o depósito internacional, tem o exame antecipado na autoridade de busca (ou busca e exame) internacional e depois faz os depósitos dos pedidos correspondentes em diversos países. A rota "B" é a tradicional (sem utilizar o PPH). Nela, o requerente, mesmo tendo uma opinião favorável sobre a patenteabilidade, resolve esperar na fila. Na rota "A" o requerente não utiliza a opinião favorável da autoridade internacional e solicita o exame antecipado do próprio escritório nacional (caso, por exemplo, ele não queria restringir o quadro reivindicatório ao sugerido pela ISA).

Figura 4: Requisitos do PPH-PCT

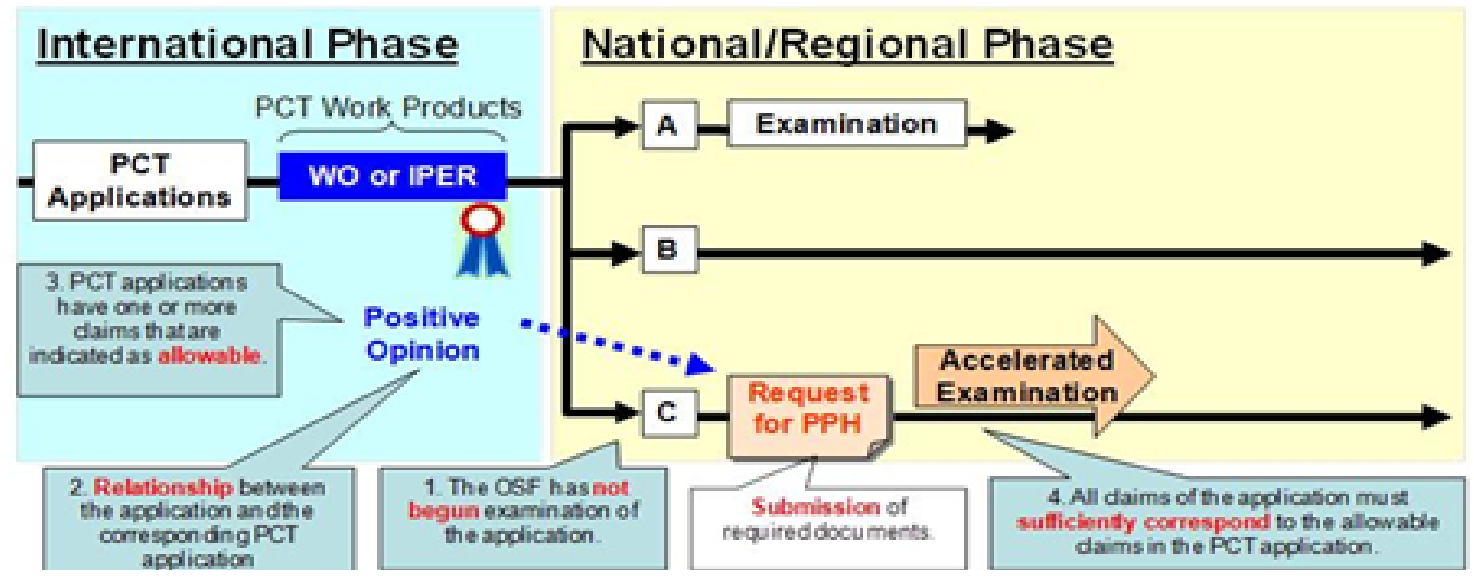

Fonte: JPO Annual Report 2011 (Japan. Japan Patent Office, 2011) 
A rota "C" é o efetivo uso do PPH. Para utilizar essa rota, os seguintes documentos devem ser apresentados juntamente com um formulário de pedido PCT-PPH:

1. Cópia das reivindicações do pedido PCT correspondente indicadas como patenteável / permitidas, e a tradução das mesmas;

2. Cópia da Opinião Escrita (Write Opinion - WO) ou do Relatório de Busca Internacional (International Search Report - ISR) ou do Relatório de Exame Preliminar Internacional (International Preliminary Examination Report - IPER) que constitui a base para os pedidos PCT-PPH, e uma tradução da mesma ${ }^{10}$;

3. Cópia dos documentos citados da busca;

4. Tabela de correspondência das reivindicações.

Qualquer um desses países que também seja signatário do PCT-PPH será chamado de "Escritório de segundo depósito" (OSF) ou "Escritório de exame posterior (OLE)". O requerente será capaz de solicitar um exame antecipado em um ou mais OLE se:

O pedido possui pelo menos uma reivindicação que foi indicada como tendo novidade, atividade inventiva e aplicabilidade industrial pelo ISA / IPEA do produto mais recente trabalho internacional:

1. Parecer Escrito da Autoridade de Busca Internacional (WO / ISA);

2. Opinião escrita da Autoridade Internacional de Exame Preliminar (WO / IPEA) ou

3. Relatório de Exame Preliminar Internacional (IPER)

4. O exame não começou no $\mathrm{OSF}^{11}$;

5. O pedido tem uma relação particular com o pedido PCT ("pedido correspondente", listado acima);

Todas as reivindicações devem corresponder suficientemente ou serem alteradas para corresponder suficientemente às reivindicações admissíveis / patenteável em PCT.

\subsection{PPH Mottainai}

O programa piloto PPH-Mottainai foi lançado em julho de 2011. Oito escritórios concordaram em lançar um piloto: JPO (Japão), USPTO (EUA), Reino Unido-IPO (UK), CIPO (Canadá), IP (Austrália), NBPR (Finlândia), ROSPATENT (Rússia) e SPTO (Espanha). A EPO (European Patent Office) começou o piloto do "PPH mottainai" em 29 de janeiro de 2012, o DPMA (Alemanha) em novembro de 2012 e o INPI (de Portugal) em 1 de Janeiro de 2013. Este acordo multilateral é o único que não apresenta variações de requisitos 10 Em diversos acordos, os candidatos não são obrigados a apresentar a cópia das reivindicações, nem dos documentos WO, nem do ISR, nem do IPER nem das traduções caso estes estejam disponíveis no site da OMPI (Organização Mundial da Propriedade Intelectual).

11 Alguns acordos PPH-Paris permitem que o requerente solicite o exame acelerado, mesmo que o exame já tenha começado no OSF (por exemplo, Coréia, Dinamarca, Finlândia, Áustria, Hungria e Espanha). 
entre os países assinantes (Japan. Japan Patent Office, 2012?b).

$\mathrm{O}$ programas Paris-rout-PPH aceita pedidos de antecipação de exame, apenas baseado nos resultados do exame do OFF (o escritório de patentes no qual o pedido correspondente foi depositado primeiro). Esta restrição criou um "desperdício" (mottainai em japonês), pois os resultados de exames de outros países poderiam ser úteis, mas não são aproveitados (Japan. Japan Patent Office, 2012?b).

Assim, surgiu a ideia do programa piloto chamado PPH-Mottainai (Portal PPH, 2012). Nesse acordo, desaparece a relação entre OSF e OFF. O requerente pode depositar um pedido " $\mathrm{A}$ " e seus pedidos correspondentes em vários países membros do PPH-Mottainai em qualquer ordem de depósito (bem como em outros países não assinantes do acordo). Quando o primeiro país membro do PPH-Mottainai realizar o exame, este escritório será chamado de Office of Early Examination (Escritório de exame anterior ou OEE). Isto permite ao requerente solicitar o exame antecipado em um ou mais dos demais países signatários do programa. Tais escritórios são chamados a Office of Late Examination (Escritório de Exame posterior ou OLE) (Figura 5). Isso elimina o desperdício que havia nos programas anteriores quando o OSF examinava o pedido antes e não podia ter seus resultados utilizados para work-sharing e exame antecipado nos demais escritórios (Japan. Japan Patent Office, 2012?b).

Figura 5: Comparativo de rotas dos diferentes tipos de PPH

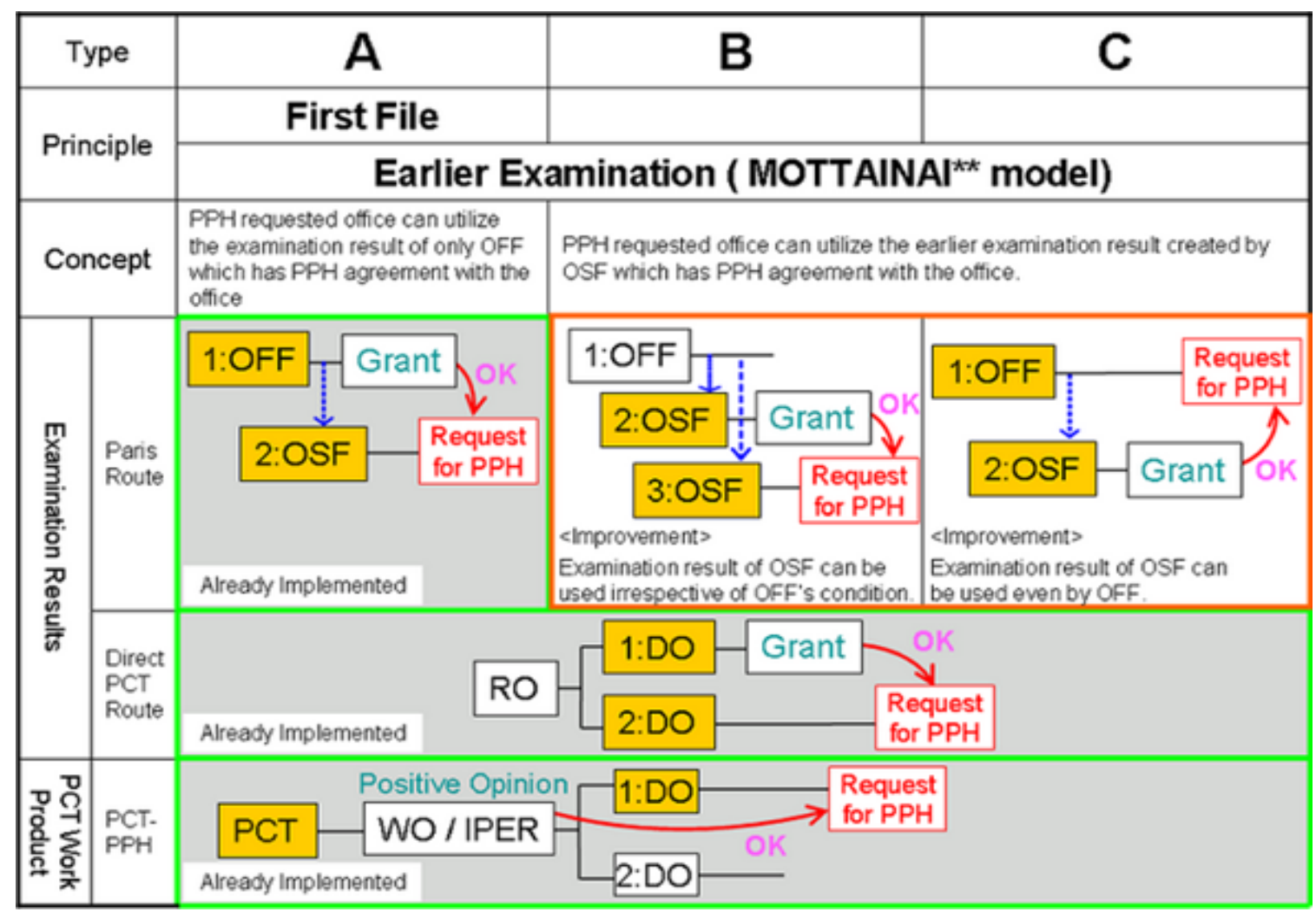

PPH Portal website (Japan. Japan Patent Office, 2012?b) 


\subsection{Global PPH (GPPH)}

O Global-PPH foi o último programa a ser lançado, no dia 6 de janeiro de 2014, e ainda está em fase piloto. O programa pode ser entendido como a junção dos três programas descritos acima. Por conseguinte, no GPPH, um pedido de processamento acelerado pode ser feito em qualquer escritório participante com base em qualquer resultado emitido por qualquer dos outros PTOs participantes (incluindo os resultados do PCT - o que o difere do PPH-Mottainai).

O GPPH visa simplificar e melhorar a rede de PPH existente para que ele seja mais acessível para os usuários. Para tanto, irá utilizar um único conjunto de requisitos de qualificação. Além do mais, os escritórios participantes avaliarão periodicamente e trocarão informações sobre a situação e a eficácia do GPPH piloto, e poderão considerar modificar o programa em função dos resultados da avaliação. Este quadro pode ser alterado a qualquer momento, com o consentimento de todos os escritórios participantes envolvidos.

Como os demais acordos, os países signatários não necessitam alterar sua legislação para participar. Por outro lado, os Escritórios participantes podem, se o desejarem, desenvolver normas específicas para, por exemplo, adequar a terminologia e os processos legais ao programa. No entanto, os critérios para a aceitação do pedido de patente no programa são padronizados de modo a proporcionar um sistema uniforme para os candidatos, ou seja, se forem cumpridos os requisitos do GPPH piloto, específicados abaixo, o pedido poderá utilizar o $\mathrm{PPH}$ :

1. Os pedidos depositados no Escritório de Exame Anterior (OEE) e do Escritório de Exame Posterior (OLE) reivindicam a mesma data mais antiga (que pode ser a data de prioridade ou a data do depósito);

2. O OEE considerou pelo menos uma reivindicação passível de ser patenteável. Qualquer relatório de exame substantivo do OEE serve para indicar que a reivindicação é passível de proteção patentária, contanto que a declaração seja explícita. Os resultados do PCT que aleguem que pelo menos uma reivindicação tem novidade, inventiva e aplicação industrial serve para indicar que a reivindicação é passível de proteção;

3. Todas as reivindicações apresentadas para exame sob o esquema do GPPH piloto no OLE devem corresponder suficientemente a uma ou mais das reivindicações consideráveis patenteáveis no OEE;

4. O OLE não começou exame de mérito do pedido. No entanto, é permitido ao OLE, caso deseje, optar por aceitar os pedidos já iniciados apresentados via GPPH dependendo das circunstâncias e necessidades do OLE e seus interessados locais; e

5. O pedido de exame de mérito deve ter sido apresentado no OLE até o momento da solicitação GPPH.

No caso de dois ou mais escritórios participantes terem um arranjo de 
programas PPH bi-lateral pré-existente, as diretrizes do piloto Global-PPH tem precedência sobre as do acordo bi-lateral existente para a duração do piloto.

\section{Conclusões}

$\mathrm{O}$ primeiro ponto do $\mathrm{PPH}$ é sua possibilidade de ser incorporado localmente sem alteração da legislação e dos procedimentos dos Escritórios de Patente Nacionais. Por não alterar a legislação local, o PPH se constitui num instrumento de cooperação técnica entre escritórios, tratando, tão somente, de um acordo bilateral de natureza operacional.

Os instrumentos de compartilhamento de trabalho entre Escritórios de Patentes funcionam bem, mas carecem, em sua maioria de uma maior participação do requerente. Assim o PPH "convoca" o depositante a auxiliar na redução do backlog. Pelo lado do solicitante, o PPH permite que obtenham as patentes de "pedidos correspondentes" de modo mais rápido em diversos escritórios. Pelo lado do escritório de patentes, o PPH que agiliza o exame de pedidos de patente de invenção, sem comprometer-lhe a qualidade e soberania. Pelo contrário, os escritórios podem (ou não) aproveitar os procedimentos de busca $^{12}$, avaliação e julgamento já existentes dos demais participantes do acordo como subsidio ao exame da patente com mais informações, mas a patente deverá cumprir todas as restrições técnicas impostas pelo Examinador local para ser concedida no país.

Além do mais, as reivindicações negadas no primeiro escritório com base nos critérios de patenteabilidade deixam de ser examinadas, mas o mesmo não ocorre com as reivindicações aceitas. Estas sempre são examinadas pelo segundo escritório, na forma da lei vigente no país que o abriga. Por isso, o programa em momento algum negligencia a soberania do exame nacional, pois nenhum dos acordos nos moldes do PPH resulta alteração na forma de decisão dos direitos patentários. O exame na íntegra é realizado com autonomia em cada escritório. A colaboração dos resultados de busca e exames representa, tão somente, dados adicionais que irão propiciar uma redução no desperdício de tempo do processo de análise patentária. A intenção é que buscas e exames sobre um mesmo pedido possam ser compartilhados entre os examinadores de ambos os escritórios, possibilitando uma redução da quantidade de exames em espera, sem perda da qualidade dos mesmos.

Como qualquer acordo internacional, há vantagens e desvantagens para os Escritórios de Patente e para os usuários do sistema de PI. Cada escritório deve avaliar os prós e contras antes de assinar o acordo comdizente com a realidade de sua indústria local e projeções do futuro. Uma sugestão de trabalhos futuros é identificar na bibliografia as principais vantagens e críticas feitas ao programa

\footnotetext{
12 Em dezembro de 2012 foi feita uma busca exaustiva de todos os acordos sobre o PPH e nenhum exigia, nem sugeria que o exame feito por outro escritório fosse aceito. A única legislação encontrada que poderia representar uma perda de autonomia, foi o guia de exame do escritório Japonês de Patentes (JPO) o qual 'recomenda' que seja considera a busca (e somente a busca, não o exame nem o julgamento) do escritório que fez o exame primeiro. Contudo, tal característica não é do acordo PPH, e sim a forma como o JPO adequou o programa, exclusivamente em sua legislação, a suas demandas locais.
} 
na literatura e avaliar seu impacto sobre os países assinantes do acordo, em especiais os emergentes.

\section{Referências}

Arai, H. (1999). Intellectual Property Policies for the Twenty-First Century: The Japanese Experience in Wealth Creation. Geneve: Wipo.

Brasil. Instituto Nacional da Propriedade Industrial. (2012). Publicações. Acesso em 25 de setembro de 2013, disponível em Portal do INPI: https://docs.google.com/ viewer?url=http://www.inpi.gov.br/images/docs/livro_inpi_portugues_final.pdf

Godici, N. (201_). The Patent Prosecution Highway. Acesso em 03 de March de 2012, disponível em Birch, Stewart, Kolasch \& Birch LLP: http://www.bskb.com/docs/ PP-Highway-NG-32310.pdf

Grubb, P. W. (2007). The Trilateral cooperation. Journal of Intellectual Property Law \& Practice, 2(6), pp. 397 - 401.

Helfgott, S. (May de 2008). Patent offices should embrace the PCT, not the PPH. Managing Intellectual Property, p. 30.

IP5. (2010-2). fiveIPoffices. Retrieved March 03, 2012, from About us: http://www. fiveipoffices.org/about-us.html

Japan Intelectual Property Association. (05 de August de 2011). International Activities. Acesso em 03 de 03 de 2012, disponível em Japan Intellectual Property Association Website: http://www.jipa.or.jp/english/activities/international/index. html

Japan. Japan Patent Office. (June de 2008). New Intellectual Property Policy for ProInnovation: Intellectual Property System as Global Infrastructure. Acesso em 03 de March de 2012, disponível em Japan Patent Office Website: http://www.jpo. go.jp/iken_e/pdf/iken_e_innovation/draf_report.pdf

Japan. Japan Patent Office. (13 de October de 2011). JPO Annual Report 2011. Acesso em 03 de March de 2012, disponível em Japan Patent Office Website: http://www.jpo.go.jp/shiryou_e/toushin_e/kenkyukai_e/pdf/annual_report2011/ part1.pdf

Japan. Japan Patent Office. (01 de Julho de 2012?a). Patent Prosecution Hightway Portal Site. Acesso em 28 de janeiro de 2014, disponível em About PPH: http:// www.jpo.go.jp/ppph-portal/aboutpph.htm

Japan. Japan Patent Office. (2012?b, Março 01). Patente Prosecution Highway Portal Site. Retrieved 01 18, 2014, from PPH MOTTAINAI: Pilot Set to Launch: http:// www.jpo.go.jp/ppph-portal/mottainai.htm

Japan. Japan Patent Office. (2014, Janeiro 6). Global Patent Prosecution Highway simplifies existing network. Retrieved 01 28, 2014, from Patent Prosecution Highway Portal Site: http://www.jpo.go.jp/ppph-portal/globalpph.htm

Maeda, K. (2011). Patent Examination Practices Designed to Improve User Convenience. Acesso em 03 de March de 2012, disponível em Institute of Intellectual Property: http://www.iip.or.jp/e/e_summary/pdf/detail2010/e22_07. pdf 
Meji, F. K., \& Suhr-Jessen, B. (January de 2011). Patent Prosecution Highway (PPH) - a fast-track to patents. Acesso em 03 de March de 2012, disponível em Danish Patent and Trademark Office: http://www.jpo.go.jp/ppph-portal/events/dkpto_ presentation.pdf

Musskopf, D. B., \& Tanaka, Y. (março de 2012). Publicações Wipo. Acesso em 03 de 2013, disponível em Japan Patent Office: http://www.jpo.go.jp/torikumi_e/ kokusai_e/pdf/ipcoop_asia-pacific_e/2011wipo_brazil.pdf

Nagano, D. (02 de July de 2010). Expectations for PPH y by Japanese Users. Acesso em 03 de March de 2012, disponível em Japan Intellectual Property Association: http://www.jpo.go.jp/torikumi_e/t_torikumi_e/pdf/highway_userseminar/jipa_ happyo_e.pdf

Ono, S., \& Ueda, M. (June de 2009). Patent Prosecution Highway in Japan. Yuasa and Hara Intellectual Property News, 27, pp. 1-4.

Peçanha, R. M. (2012). "Exame Acelerado de Patentes: abordagem estratégica e proposição de metodologia de implantação. Rio de Janeiro: FGV.

Sadasivan, A. (22 de April de 2010). A super fast track to the grant of patents in Singapore and the USA. Journal of Intellectual Property Law\&Practice, 5(6), pp. 459-464.

Simões, J. (23 de April de 2011). Brasil adia acordo com EUA para evitar duplicidade no exame de patentes. (Unicamp) Acesso em 03 de 03 de 2012, disponível em Inovação Unicamp: http://www.inovacao.unicamp.br/noticia.php?id=911

Thomas, J. R. (28 de July de 2011). Congressional Research Service: Recent Developments in Patent. Acesso em 03 de March de 2012, disponível em IEEE USA Website: http://ieeeusa.org/policy/eyeonwashington/2011/documents/ recentdeveloppatentadmin.pdf

United States of America. The United States Patent and Trademark Office. (02 de March de 2011). Patent Prosecution Highway: Fast Track Examinatio of Patent Applications. Acesso em 03 de March de 2012, disponível em The United States Patent and Trademark Office Website: http://www.uspto.gov/patents/init_events/ $\mathrm{pph} / \mathrm{pphbrochure.j \textrm {sp }}$

United States of America. The United States Patent and Trademark Office. (09 de setembro de 2012). uspto.gov. Acesso em 26 de setembro de 2013, disponível em Accelerated Examination: http://www.uspto.gov/patents/process/file/accelerated/ index.jsp

Wernli, M., \& Bowley, C. (12 de October de 2011). Introduction to Patent Prosecution Highways (PPH). Acesso em 03 de March de 2012, disponível em Fish \& Richardson Website: http://www.fr.com/files/uploads/Documents/Patent\%20 Prosecution\%20Highway\%20-\%20Webinar\%20October\%202011\%20FINAL.pdf

World Intellectual Property Organization. (2011). World Intellectual Property Indicators, 2011 edition. Economics and Statistics Division. Geneve: Wipo. 
